\title{
Formulation of Synthesized Zinc Oxide Nanopowder into Hybrid Beads for Dye Separation
}

\author{
H. Shokry Hassan, ${ }^{1}$ M. F. Elkady,${ }^{2,3}$ A. H. El-Shazly, ${ }^{2}$ and Hisham S. Bamufleh ${ }^{4}$ \\ ${ }^{1}$ Electronic Materials Researches Department, Advanced Technology and New Materials Researches Institute, \\ City of Scientific Researches and Technological Applications, New Borg El-Arab City, Alexandria 21934, Egypt \\ ${ }^{2}$ Chemical and Petrochemical Engineering Department, Egypt-Japan University of Science and Technology, \\ New Borg El-Arab City, Alexandria 21934, Egypt \\ ${ }^{3}$ Fabrication Technology Department, Advanced Technology and New Materials Research Institute (ATNMRI), \\ City of Scientific Research and Technology Applications, Alexandria 21934, Egypt \\ ${ }^{4}$ Department of Chemical \& Materials Engineering, Faculty of Engineering, King Abdulaziz University, P.O. Box 80204, \\ Jeddah 21589, Saudi Arabia
}

Correspondence should be addressed to M. F. Elkady; maroelkady@yahoo.com

Received 11 December 2013; Revised 11 February 2014; Accepted 28 February 2014; Published 9 April 2014

Academic Editor: Shao-Wen Cao

Copyright (C) 2014 H. Shokry Hassan et al. This is an open access article distributed under the Creative Commons Attribution License, which permits unrestricted use, distribution, and reproduction in any medium, provided the original work is properly cited.

\begin{abstract}
The sol-gel prepared zinc oxide nanopowder was immobilized onto alginate-polyvinyl alcohol polymer blend to fabricate novel biocomposite beads. Various physicochemical characterization techniques have been utilized to identify the crystalline, morphological, and chemical structures of both the fabricated zinc oxide hybrid beads and their corresponding zinc oxide nanopowder. The thermal stability investigations demonstrate that $\mathrm{ZnO}$ nanopowder stability dramatically decreased with its immobilization into the polymeric alginate and PVA matrix. The formulated beads had very strong mechanical strength and they are difficult to be broken up to $1500 \mathrm{rpm}$. Moreover, these hybrid beads are chemically stable at the acidic media $(\mathrm{pH}<7)$ especially within the $\mathrm{pH}$ range of 2-7. Finally, the applicability of the formulated $\mathrm{ZnO}$ hybrid beads for C.I. basic blue 41 (BB41) decolorization from aqueous solution was examined.
\end{abstract}

\section{Introduction}

The huge increment in pollution level urges scientific community to research with more and more dedication in environmental remediation. One of the important classes of the pollutants is dyes; dyes have been extensively used in industries, such as textile, paper, printing, cosmetics, plastics, and rubber, for the coloration of products $[1,2]$. They usually have a synthetic origin and are based on complex aromatic structures which make them stable and difficult to be biodegraded [1]. A small quantity of dyes can color large water bodies, which not only affects aesthetic merit but also reduces light penetration and photosynthesis. Moreover, many dyes are toxic in nature with suspected carcinogenic and mutagenic effects that affect aquatic biota and also human beings $[3,4]$. Therefore, the decolorization of dye-containing effluents is considered compulsory prior to discharge by the environmental regulations in most of the countries $[5,6]$. In this respect, C.I. basic blue 41 (BB41) is a mono-azo-basic dye of bright blue hue; it is particularly suitable for dyeing acrylic substrates and can also be applied to some polyamide and polyester types, viscose, cotton, and wool. It is also effective as strainer for the identification of avian leukocytes and blood and bone-marrow cells [7]. This basic dye may be considered as one of the most toxic substances. It can cause eye burns which may be responsible for permanent injury to the eyes of human and animals. On inhalation, it can give rise to short periods of rapid or difficult breathing while ingestion through 
the mouth produces a burning sensation and may cause nausea, vomiting, profuse sweating, mental confusion, and methemoglobinemia $[8,9]$. Consequently, BB41 is selected as one of the simulated dye pollutants to assess its sorption behavior to be eliminated from polluted wastewaters.

Different techniques have been reported by various investigations for the removal of dyes from water and wastewater, including biological processes, combined chemical and biochemical processes, chemical oxidation, adsorption, coagulation, and membrane treatments; each of these has specific advantages and disadvantages. Among these several conventional chemical and physical methods, the adsorption process is one of the effective techniques that have been successfully employed for dye removal from wastewater. Adsorption is a classical technique which involves a variety of highly porous adsorbents to ensure adequate surface area for adsorption [10]. Accordingly, many porous adsorbent materials have been tested on the possibility for dye removal such as activated carbon [11], peat, chitin, and silica [12]. However, intraparticle diffusion associated with porous adsorbents may reduce the adsorption rate and capacity [13]. Consequently, there is a need to develop alternative novel adsorbents with both large surface area and small diffusion resistance characteristics. Recent advances in the field of nanotechnology offer a class of promising adsorbents that are ultrafine and characterized by their large surface area. Nanosized metal oxide nanoparticles have received considerable attention due to the simple procedure involved in synthesis with low capital cost compared to commercially available activated carbon. Diverse inorganic metal oxides may serve as good adsorbents, due to their relatively high surface area and thermal and chemical stabilities. Among these metal oxide nanopowders, Zinc oxide was distinguished by its significant sorption properties toward the polluted harmful ions presence in wastewater [14].

A wide number of methods have been used to prepare $\mathrm{ZnO}$ nanopowders, including homogeneous precipitation in aqueous solution of $\mathrm{Zn}^{2+}$ cations, hydrothermal synthesis, microwave synthesis, solution combustion, pulsed laser deposition, emulsion precipitation, ultrasonic atomization, spray pyrolysis, freeze-drying, and sol-gel processes [15-17]. Regarding the various stated preparation techniques, sol-gel represents one of the fastest growing fields of contemporary chemistry. Accordingly, this preparation technique was utilized for synthesis of $\mathrm{ZnO}$ nanoparticles. This is due to the fact that this preparation technique offers several advantages such as being easy, fast, and able to deform materials into complex geometries in a gel state with high purity [18]. Consequently, zinc oxide nanoparticles can be easily prepared using sol-gel technique. In spite of the prepared zinc oxide nanopowder having good adsorbent for dyes, however it is difficult to be handled in the adsorption techniques due to its small size and hydrophobic nature. In order to overcome this limitation of zinc oxide nanopowder, incorporation of a polymer material with the inorganic metal oxide provides an innovative class of hybrid materials [19]. Many investigators have introduced organic-inorganic hybrid changers consisting of inorganic sorbent materials and organic binding matrices $[20,21]$.
These materials have conjugated the mechanical properties of the organic polymers with the intrinsic properties of the inorganic compound creating a new class of hybrid organic-inorganic materials with improvement in mechanical properties, chemical inertness, high temperature and radiation stability, reproducibility, and high selectivity for harmful ions. Consequently, inorganic zinc oxide sorbent material may be encapsulated into porous polymeric matrices through the immobilization technique. The porous structure of polymer matrices allows the harmful ions to diffuse into the internal pores and be adsorbed into the internal sorbent materials. So, the major focus was to select a suitable support polymeric material for the immobilization of the synthesized $\mathrm{ZnO}$ nanopowder. Various polymer matrices have been employed as immobilized matrix such as alginate, agar, polyacrylamide, chitosan, carrageenan, cellulose acetate, and polyvinyl alcohol (PVA) [22]. PVA may be considered as the largest synthetic water soluble polymer produced in the world and its application as an immobilized polymer matrix was initiated about 20 years ago $[23,24]$. PVA is a polymer of great interest because of its desirable characteristics specifically for various pharmaceutical and biomedical applications [23]. PVA offers various advantages over the conventional alginate hydrogels including lower cost, higher durability, and chemical stability and its nontoxicity to viable cells [25]. However, the agglomeration problem that is associated with PVA gel beads is still the main drawback for utilizing PVA as immobilizing polymer matrix. Nevertheless, it is still used by many researchers through adding sodium alginate; thus the agglomeration of PVA gel beads can be reduced [26]. The combination of sodium alginate and PVA has already been reported in PVA-boric acid method, but usually the concentration of sodium alginate was below $0.4 \%$. Generally, sodium alginate used at such low concentration would prevent the agglomeration of PVA gel beads [27]. In the present investigation, we are concerned with formulation of the synthesized zinc oxide nanopowder into innovative biocomposite beads, through the incorporation of $\mathrm{ZnO}$ into polymer blend of alginate and PVA. According to our best knowledge, this is the first report that deals with $\mathrm{ZnO}$ nanoparticles immobilized into mixed polymer matrices composed of alginate and PVA. So, the main focus of this study is to investigate the physicochemical properties of the fabricated zinc oxide biocomposite beads and their corresponding zinc oxide nanopowder. The feasibility of the formulated hybrid beads towards dye decolorization will be assigned. The variation in the operational parameters that affect behavior of the fabricated biocomposite beads will be examined.

\section{Materials and Methods}

2.1. Materials. The selected polluted dye model is the azo dye C.I. basic blue 41 (BB41) that was provided by Ciba Specialty Chemicals Inc. and was utilized without further purification; its characteristics and molecular structure are investigated in Table 1. A stock solution of $1000 \mathrm{mg} / \mathrm{L}$ was prepared by dissolving $1 \mathrm{~g}$ of dye powder in distilled water to prevent and 
TABLE 1: Chemical properties of C.I. basic blue 41 dye.

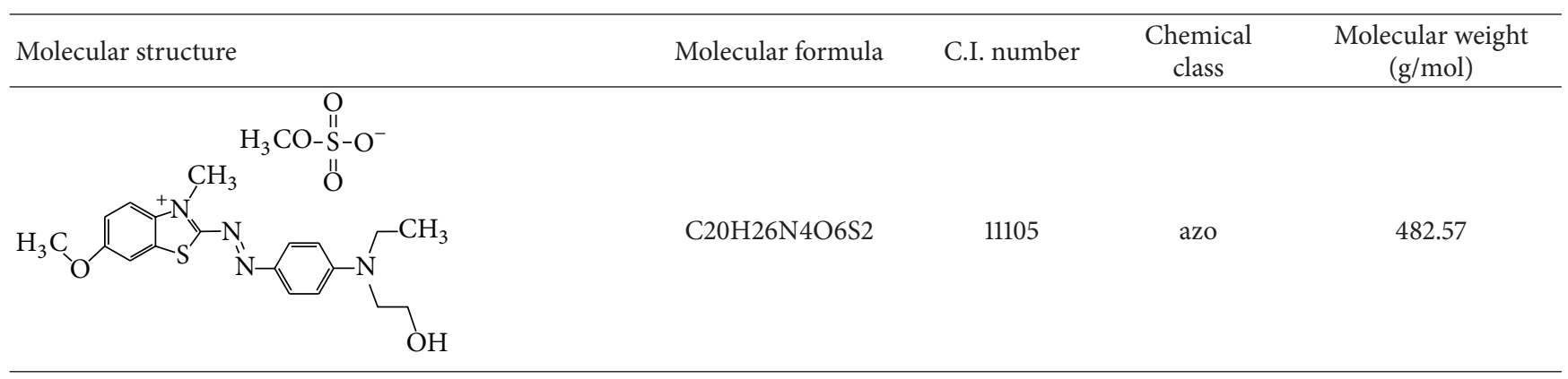

minimize possible interferences and then used for further studies by diluting as required. Zinc chloride, sodium alginate, polyvinyl alcohol, hydrochloric acid, sodium hydroxide, ethanol, and other reagents used in this work were all A.R. grade reagents.

\subsection{Synthesis of ZnO Nanopowder Using Sol-Gel Precipitation} Technique. An ammonium hydroxide solution (1M) was added dropwise into a solution of $0.2 \mathrm{M}$ zinc chloride in the presence of polyvinylpyrrolidone (PVP) with constant stirring till the solution $\mathrm{pH}$ is adjusted at 10 . The reaction temperature of the solution mixture was maintained at $70^{\circ} \mathrm{C}$ under constant stirring overnight. The formed fine powder was separated and washed several times with distilled water and ethanol. The washed precipitate was then dried by gentle heating at $50^{\circ} \mathrm{C}$. Then the product is ground into fine powder to be immobilized into the polymer matrix.

2.3. Fabrication of $\mathrm{ZnO}$ Hybrid Beads ( $\mathrm{ZOHB}$ ). $25 \mathrm{~g}$ of PVA has been dissolved in $250 \mathrm{~mL}$ of distilled water in the presence of known weight of sodium alginate until attaining clean aqueous solution. After complete dissolution of polymer matrix, $20 \mathrm{~g}$ from the synthesized zinc oxide nanopowder has been dispersed into the previous solution. The suspended $\mathrm{ZnO}$ slurry was stirred continuously using the homogenizer to ensure the complete nano-zinc oxide dispersion into the polymeric solution mixture. The resultant $\mathrm{ZnO}$ polymeric slurry was pumped into the cross-linker solution mixture composed of $3 \% \mathrm{CaCl}_{2}$ and $5 \%$ boric acid to be formulated into microbeads. The formed spherical beads were maintained under gentle stirring overnight to complete their gelation. The formulated beads were separated from the cross-linker solution and washed several times with distilled water and then dried at $40^{\circ} \mathrm{C}$.

2.4. Characteristic Features of Fabricated $\mathrm{ZnO}$ Hybrid Beads and Their Corresponding Nano-Zinc Oxide. Various physicochemical characterization techniques have been utilized to identify the crystalline, morphological, and chemical structures for both the fabricated zinc oxide hybrid beads and their corresponding zinc oxide nanopowder.

In order to identify the main functional groups responsible for the dye sorption process, FT-IR spectra (Shimadzu
FTIR-8400 S) of synthesized zinc oxide before and after its fabrication into hybrid beads were examined using $\mathrm{KBr}$ disc technique over the wide wavelength range $500-4000 \mathrm{~cm}^{-1}$.

The morphological structures of the synthesized nanozinc oxide and its polymeric hybrid beads were detectable using JEOL JSM 6360LA scanning electron microscope (SEM). Chemical elemental analyses of these two samples were performed using the energy-dispersive X-ray spectroscopy (EDX) unit that combined with SEM equipment.

The crystal structures of both zinc oxide nanopowder and its polymeric hybrid were determined using X-ray diffractometry (Shimadzu-7000 diffractometer) with $\mathrm{Cu} \mathrm{K} \alpha$ radiation beam $(\lambda=0.154060 \mathrm{~nm})$.

The thermal properties of both zinc oxide nanopowder and its polymeric hybrid were investigated over temperature range from ambient condition up to $800^{\circ} \mathrm{C}$ with a heating rate of $20^{\circ} \mathrm{C} / \mathrm{min}$ in flowing $\mathrm{N}_{2}$ using Thermal Gravimetric Analysis (Shimadzu TGA-50).

The BET surface area of nano-zinc oxide and its polymeric hybrid was calculated from the nitrogen gas adsorption using the Chemisorption-Physisorption analyzer (Beckman Coulter AS3100, USA).

The chemical stability of the prepared zinc oxide polymeric hybrid toward the hydrogen ion concentration was determined. Different acidic solutions in $\mathrm{pH}$ range $1-5$ were prepared using hydrochloric acid. On the other hand, different alkaline solutions in $\mathrm{pH}$ range 8-12 were prepared using sodium hydroxide. The synthesized hybrid beads were immersed into these different acidic and alkaline solutions for $48 \mathrm{~h}$. After this period the wetted beads were separated and then rinsed with distilled water and dried at $60^{\circ} \mathrm{C}$ until reaching constant weight [28].

The mechanical stability of the prepared zinc oxide polymeric hybrid beads was assigned using mechanical strength test. This test was performed using homemade designed plexiglass beaker divided into 4 equal segments through baffles $(1 \mathrm{~cm}$ width). The cylindrical dimension of the beaker was $11 \mathrm{~cm}$ in diameter and $13 \mathrm{~cm}$ in height. One gram from zinc oxide hybrid beads was added to the beaker followed by $200 \mathrm{~mL}$ distilled water. The hybrid beads were agitated in the beaker for $72 \mathrm{~h}$ at different controlled mixing speed that varied from $500 \mathrm{rpm}$ to $3000 \mathrm{rpm}$. The turbidity measurements were detected after the mixing period for each mixing speed. The remaining beads after mixing were 
counted and then dried in a desiccator until no further change in weight was detected. Each run was performed in triplicate and the average measurements were recorded.

2.5. Evaluation of the Decolourization Behaviour of Fabricated $\mathrm{ZnO}$ Hybrid Beads. The decolourization availability of BB41 dye onto the fabricated $\mathrm{ZOHB}$ was evaluated through the batch adsorption technique using shaking incubator. Stock solution of BB41 dye $(100 \mathrm{mg} / \mathrm{L})$ was prepared. In a typical experiment, a known amount of dry $\mathrm{ZnO}$ hybrid beads was mixed with $25 \mathrm{~mL}$ of dye solution with specific concentration at conical flask and kept under constant agitation of $400 \mathrm{rpm}$ for 60 minutes in the shaker incubator at different temperatures. After finishing the mixing period, the residual dye concentration was determined calorimetrically through measuring the absorbance of the dye solution at $610 \mathrm{~nm}$ using a UV-vis double beam spectrophotometer (Labomed model). The corresponding dye concentration in the supernatant solution was obtained using a previously constructed calibration graph. All the experiments measurements were carried out in duplicate and mean values are presented. The percentage decolourization efficiencies were then obtained using the following equation:

$$
\% \text { dye decolourization }=\left(\frac{\left(C_{0}-C\right)}{C}\right) * 100 \text {, }
$$

where $C_{0}$ is the initial dye concentration $(\mathrm{mg} / \mathrm{L})$ and $C$ is the final dye concentration in aqueous solution after phase separation $(\mathrm{mg} / \mathrm{L})$.

The $\mathrm{ZOHB}$ adsorption capacities were evaluated using the following mass balance equation:

$$
Q(\mathrm{mg} / \mathrm{g})=\frac{V\left(C_{0}-C\right)}{M},
$$

where $Q$ is the stain uptake capacity $(\mathrm{mg} / \mathrm{g}), C_{0}$ and $C$ are the initial and final dye concentrations $(\mathrm{mg} / \mathrm{L}), V$ is the volume of dye solution $(\mathrm{mL})$, and $M$ is the $\mathrm{ZOHB}$ mass $(\mathrm{g})$.

The equilibrium behavior of the basic dye adsorption process onto the fabricated beads was established using Langmuir and Freundlich equilibrium isotherm models. Moreover the kinetic of dye adsorption process was tested using the pseudo-first- and pseudo-second-order kinetic models.

\section{Result and Discussion}

3.1. Characteristic Features of Fabricated $\mathrm{ZnO}$ Hybrid Beads and Their Corresponding Nano-Zinc Oxide. Comparable investigation was established between the fabricated zinc oxide polymeric hybrid and its corresponding zinc oxide nanopowder to declare their characteristic properties.

3.1.1. Crystalline Structure Identification Using XRD. The XRD patterns of pure zinc oxide nanopowder (Figure $1(A)$ ) clearly demonstrated that all the diffraction peaks of the formed $\mathrm{ZnO}$ nanoparticles can be indexed to the hexagonal wurtzite structure with high degree of crystallinity [29],

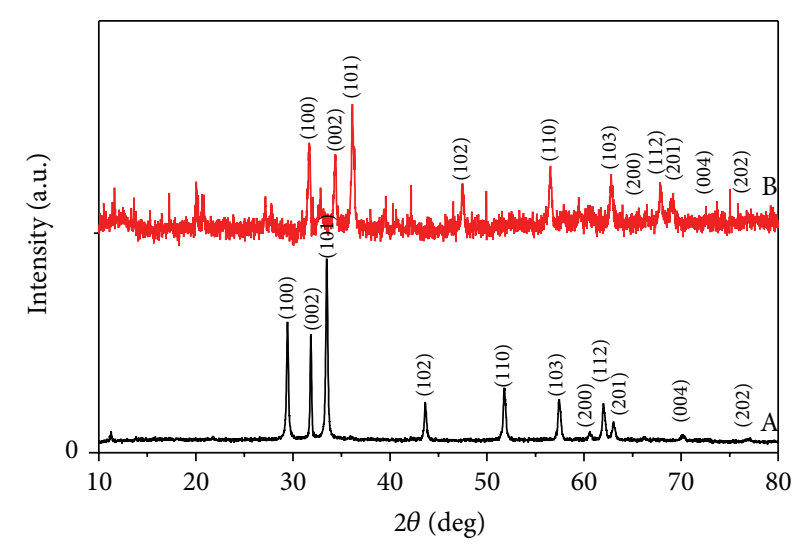

A: pure $\mathrm{ZnO}$

B: $\mathrm{ZnO}$ polymeric hybrid beads

FIGURE 1: XRD spectrums of synthesized pure zinc oxide and its corresponding polymeric hybrid.

which is in good agreement with the value obtained by JCPDS (card number 01-089-1397). Comparing this spectrum with the $\mathrm{ZnO}$ reference card, no impurity phase was detected in the XRD pattern of the synthesized $\mathrm{ZnO}$. The main $\mathrm{ZnO}$ characteristic diffraction peaks and their orientation planes for the prepared $\mathrm{ZnO}$ and its polymeric hybrid were indexed in Figure 1.

However, after immobilizing the prepared nano-zinc oxide onto the polymeric matrix composed of alginate and PVA blend to fabricate the hybrid beads, a new broad peak at $2 \theta=19.6^{\circ}$ has appeared (Figure $1(\mathrm{~B})$ ) beside the previous identified $\mathrm{ZnO}$ peaks. The broadening of this peak illustrates the amorphous nature of alginate/PVA polymer blend. This amorphous behaviour may be due to any weak interaction that happened between the two polymers on blending [30]. In fact, PVA structure is collapsed during the complex formation generating the small crystallites and hence an increase in interconnection between two phases leads to the broadening of the peak. This characteristic peak confirms alginate and PVA blending, where if the two polymers have not blended properly, all the respective peaks of both the polymers would have been seen separately which is not present at this case study [31]. Noticeable peak intensities decayed at the fabricated hybrid beads for all $\mathrm{ZnO}$ characteristic peaks compared with that presented at the pure zinc oxide nanopowder. This reduction in peaks intensities for the fabricated $\mathrm{ZnO}$ hybrid beads was associated with XRD spectrum distortions. This may be attributed to the introduction of the amorphous polymer blend shell matrix that immobilized the nanopowder zinc oxide [32].

3.1.2. Chemical Structure Identification Using FTIR. FTIR analysis technique is utilized to recognize the materials chemical bonding. It is used to identify the elemental constituents of a material. The characteristic peaks exhibited by 


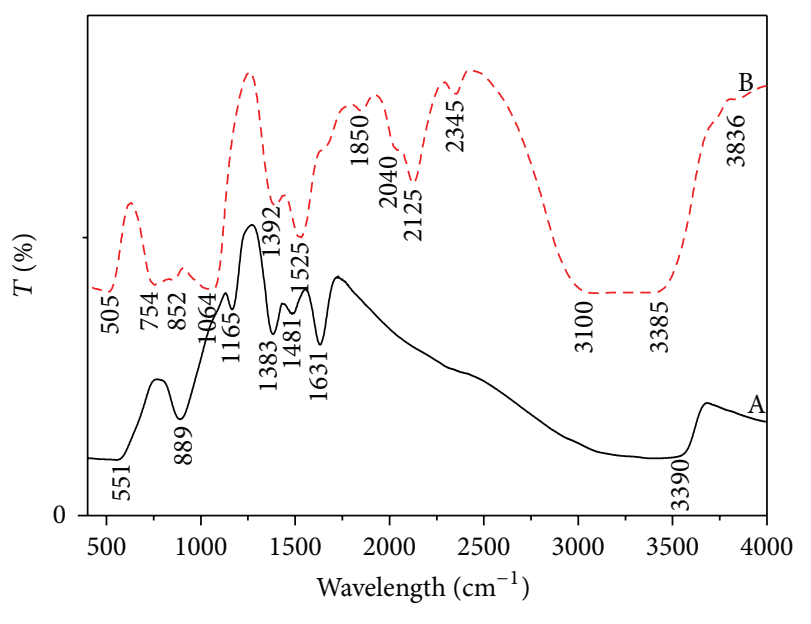

A: pure $\mathrm{ZnO}$

$\mathrm{B}: \mathrm{ZnO}$ polymeric hybrid beads

FIGURE 2: FTIR analysis of synthesized pure zinc oxide and its corresponding polymeric hybrid.

FTIR spectrums of both zinc oxide hybrid beads and their corresponding nano-zinc oxide were investigated in Figure 2.

All zinc oxide characteristic peaks appeared at the $\mathrm{ZnO}$ polymeric hybrid with slight peaks shifting due to presence of the polymer blend matrix that confirm $\mathrm{ZnO}$ immobilization onto the polymeric matrix. Where the two FTIR spectrums of $\mathrm{ZnO}$ nanoparticles and their polymeric hybrid showed identical characteristic peaks at about $551 \mathrm{~cm}^{-1}$ in case of pure $\mathrm{ZnO}$ which corresponds to the $\mathrm{Zn}-\mathrm{O}$ bond stretching vibration that shifted to about $505 \mathrm{~cm}^{-1}$ for the polymeric hybrid [33]. Moreover the medium to weak bands at $889 \mathrm{~cm}^{-1}$ for pure $\mathrm{ZnO}$ and $852 \mathrm{~cm}^{-1}$ at $\mathrm{ZnO}$ polymeric hybrid are assigned to the vibrational frequencies due to the change in the microstructural features into $\mathrm{Zn}-\mathrm{O}$ lattice [34]. The weak peaks sited at $1165 \mathrm{~cm}^{-1}$ and $1383 \mathrm{~cm}^{-1}$ for pure $\mathrm{ZnO}$ that shifted to $1064 \mathrm{~cm}^{-1}$ and $1392 \mathrm{~cm}^{-1}$ for polymeric hybrid were regarding presence of $\mathrm{C}-\mathrm{O}$ and $\mathrm{C}-$ $\mathrm{H}$ vibration modes of $\mathrm{PVP}$, which acts as a capping agent for synthesis of nano-zinc oxide [35]. The remaining $\mathrm{ZnO}$ characteristic peaks around $1600 \mathrm{~cm}^{-1}$ and $3400 \mathrm{~cm}^{-1}$ are due to normal polymeric $\mathrm{O}-\mathrm{H}$ stretching vibration of the $\mathrm{H}_{2} \mathrm{O}$ small amount inside the $\mathrm{ZnO}$ nanocrystals [36]. Considering the difference between the two spectrums of $\mathrm{ZnO}$ and its polymeric hybrid, two new peaks appear at $3100 \mathrm{~cm}^{-1}$ and $1850 \mathrm{~cm}^{-1}$ for the $\mathrm{ZnO}$ polymeric hybrid that assigned the interaction between alginate and PVA in its polymer blend matrix [31]. It is worth mentioning that the bands appearing in the region of $3100 \mathrm{~cm}^{-1}$ belong to all types of hydrogen bonded $\mathrm{OH}$ groups at the polymer blend and the bands appearing at $1850 \mathrm{~cm}^{-1}$ belong to all carboxylate groups present at the polymer matrix [37]. This FTIR analysis strongly supports the idea that hydrogen bonding could be formed between the hydroxyl groups of PVA and that group of alginate that composes the immobilized polymer matrix [37].
TABLE 2: EDX elemental analysis of formulated zinc oxide hybrid beads.

\begin{tabular}{lc}
\hline Elements & \% atomic \\
\hline $\mathrm{C}$ & 29.75 \\
$\mathrm{O}$ & 51.4 \\
$\mathrm{Zn}$ & 13.86 \\
$\mathrm{Na}$ & 2.51 \\
$\mathrm{Ca}$ & 1.38 \\
$\mathrm{~B}$ & 1.1 \\
\hline
\end{tabular}

3.1.3. Morphological Structure Identification Using SEM. SEM imaging is one of the promising techniques for the topography study of the prepared samples, where it gives important information regarding the shape and size of the synthesized particles. The surface morphology of the prepared zinc oxide and its corresponding polymeric hybrid beads is illustrated in Figures 3(a)-3(c). The first entire SEM picture (Figure 3(a)) clearly showed that the as-prepared zinc oxide produced from the sol-gel technique composed of agglomerated nanoparticles with spherical shapes.

The average size of these sphere particles is of nanometer size order with average diameter equivalent to $40 \mathrm{~nm}$. The incorporation of these $\mathrm{ZnO}$ nanoparticles onto the polymeric hybrid matrix beads was explored in the beads cross-section image (Figure 3(b)). The small lighted spots presence in the bead cross-section area is repressive for $\mathrm{ZnO}$ nanoparticles that immobilized onto alginate and PVA polymeric matrix. The homogeneity and uniform distribution of $\mathrm{ZnO}$ nanoparticles onto the polymeric matrix were observed from this image. Also, this image investigated clearly the porous structure of the formulated $\mathrm{ZnO}$ polymeric hybrid beads. The macroporous structures of the formulated $\mathrm{ZnO}$ hybrid beads were obviously clear from Figure 3(c). This micrograph investigates the open pores and cavities that are present inside the hybrid polymeric chains, which serve as host places for dye molecules entrapment during the dye sorption process onto the $\mathrm{ZnO}$ hybrid beads. In order to confirm the main constituents of the prepared hybrid beads, quantitative elemental of these beads were performed using EDX analysis. Table 2 investigates the atomic percentages of the hybrid beads elemental composition. It was indicated from this table that the beads are composed mainly of $\mathrm{C}, \mathrm{O}$, and $\mathrm{Zn}$ and traces from $\mathrm{Ca}, \mathrm{Na}$, and $\mathrm{B}$ ions. This is confirming that the main components of the hybrid beads are the host mixed polymer matrix of alginate and PVA and the immobilized $\mathrm{ZnO}$ nanoparticles.

3.1.4. Surface Area Identification Using BET. The nitrogen adsorption-desorption isotherms of zinc oxide nanopowder and its corresponding hybrid beads distinguish that both prepared materials are characterized by their high surface area. However, the calculated specific surface area of the formulated $\mathrm{ZnO}$ beads that is equal to $22.8 \mathrm{~m}^{2} / \mathrm{g}$ is comparatively less than that of the free $\mathrm{ZnO}$ nanopowder that is equivalent to $64.9 \mathrm{~m}^{2} / \mathrm{g}$. Also, the calculated pore volume of $0.132 \mathrm{~cm}^{3} / \mathrm{g}$ value for the free powdered $\mathrm{ZnO}$ is much higher 


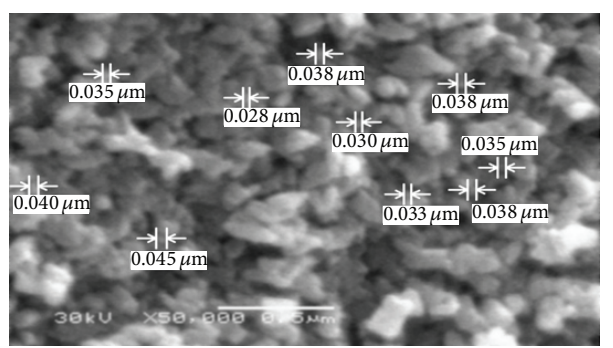

(a)

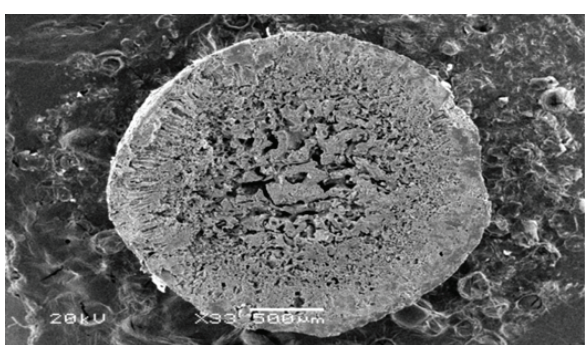

(b)

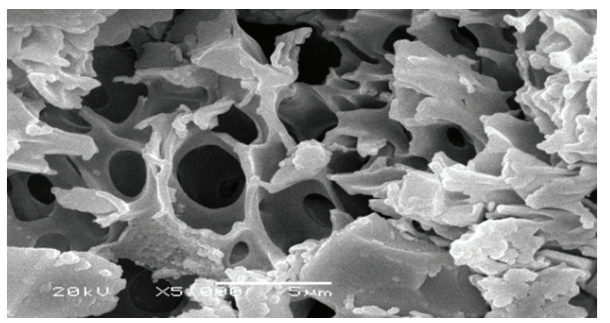

(c)

FIGURE 3: The SEM micrographs of (a) pure $\mathrm{ZnO}$ nanopowder, (b) cross-section of $\mathrm{ZnO}$ polymeric hybrid bead, and (c) internal structure $\mathrm{ZnO}$ polymeric hybrid beads.

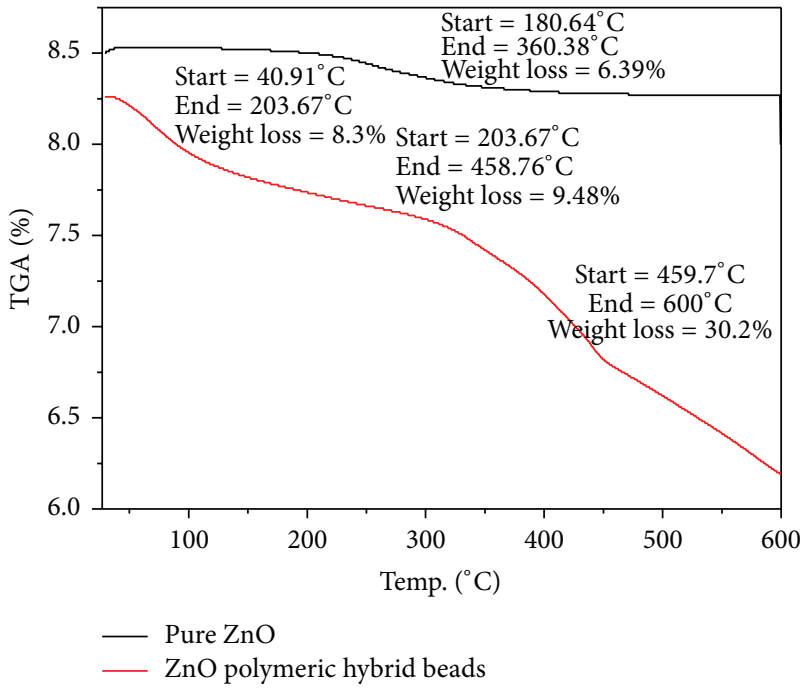

Figure 4: Thermal profiles of synthesized pure zinc oxide and its corresponding polymeric hybrid.

than that of its corresponding hybrid beads that record $4.64 *$ $10^{-2} \mathrm{~cm}^{3} / \mathrm{g}$. These results may be respective to the conversion of $\mathrm{ZnO}$ nanopowder from nanoscale particles into microscale polymeric beads.

3.1.5. Thermal Profile Identification Using TGA. The thermal profiles of both as-prepared $\mathrm{ZnO}$ nanopowder and its corresponding polymeric hybrid beads were explored in Figure 4. It was evident from this figure that the thermal stability of $\mathrm{ZnO}$ nanopowder was decreased with its immobilization into the polymeric alginate and PVA matrix.
Zinc oxide nanopowder thermal profile shows one degradation step that begins at $180^{\circ} \mathrm{C}$ and finishes at $360^{\circ} \mathrm{C}$ that represent the surface adsorbed water molecules and the decomposition of traces remaining PVP polymeric matrix that utilized as stabilizing agent during its synthesizing process. After this temperature range $\mathrm{ZnO}$ showed high thermal stabilities up to $600^{\circ} \mathrm{C}$, which is the characteristic property of all metal oxides. However, the thermal stability of $\mathrm{ZnO}$ polymeric beads is comparatively less than its parent $\mathrm{ZnO}$ nanopowder, where its thermal profile showed three main degradation steps. The first degradation step at $40-$ $200^{\circ} \mathrm{C}$ represented the physical water adsorbed onto the polymeric beads. The second degradation step at $200-460^{\circ} \mathrm{C}$ is due to the thermal degradation of the immobilized polymer matrix that is composed of PVA and alginate [31]. The final degradation step may be corresponding to the byproduct formation of PVA during the TGA thermal degradation process. According to Holland and Hay's observations [38], thermal degradation could lead to the production of aldehyde and alkene end groups in the molten state, which could lead to the formation of vinyl ester by the rearrangement [37]. This result obvious that the $\mathrm{ZnO}$ hybrid beads were less thermally stable compared with their parent $\mathrm{ZnO}$ nanopowder, which is the leak property of the polymeric materials compared with inorganic compounds.

3.1.6. Chemical and Mechanical Stabilities of $\mathrm{ZnO}$ Hybrid Beads. The hybrid beads chemical stability at the acidic media $(\mathrm{pH}<7)$ especially within the $\mathrm{pH}$ range of $2-7$ indicated that the number of beads remains constant throughout the period of experiment that is confirmed from Figure 5, where this figure investigated that there are no significant weight losses for the hybrid beads at the acidic $\mathrm{pH}$ range. This suggested the higher cross-linking inside the hybrid beads. 


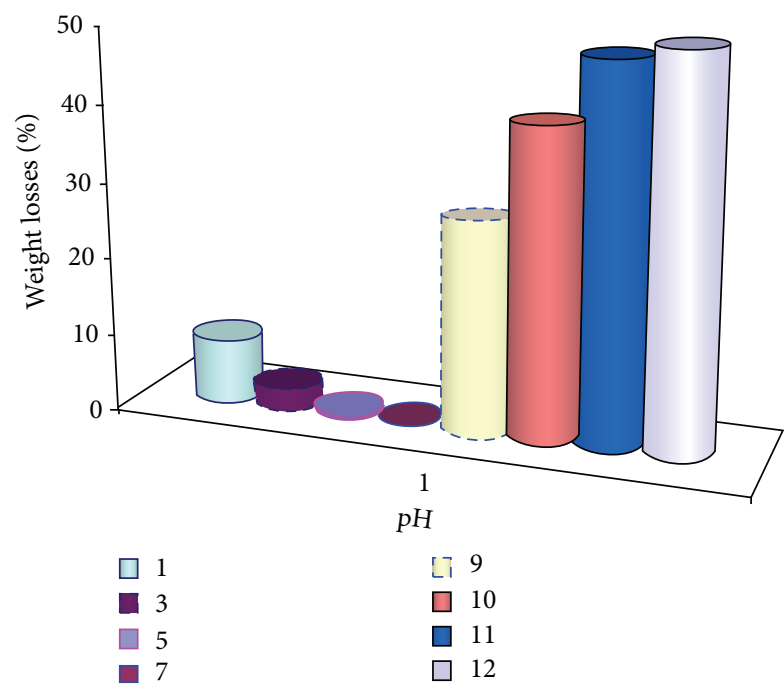

FIGURE 5: Chemical stability of prepared $\mathrm{ZnO}$ polymeric hybrid beads at various $\mathrm{pH}$ values.

Moreover, their physical appearance remains constant except that their diameter varied due to the water swelling for the porous polymeric hybrid. Accordingly, the hybrid beads were very stable within the acidic $\mathrm{pH}$ range. In contrast, regarding the alkaline media $(\mathrm{pH}>7)$, Figure 5 showed notable weight losses for the hybrid beads after drying. These results decided that the excess $\mathrm{OH}$ ions that are present in the solution media may act as a chelating agent leading to the decross-linking of the hybrid beads and leaching their immobilized zinc oxide nanopowder that declines their weight. These results are in accordance with the other researchers' founding [39].

The mechanical properties of the prepared $\mathrm{ZnO}$ hybrid beads were elucidated to determine their availability for the column operations. Figure 6 shows evidence that the formulated beads had very strong mechanical strength and they are difficult to be broken, where slight decline in weight losses was noticeable as the mixing speed improved above $1500 \mathrm{rpm}$. This is due to the rubber-like elastic properties of $\mathrm{ZnO}$ hybrid beads, where PVA contributed strength and durability to the beads while alginate improved the surface properties that reduced the tendency to agglomerate [40]. These good mechanical properties were confirmed from the turbidity measurements after the stirring period. Slight observed turbidity was noticed as the agitation speed incremented above $2000 \mathrm{rpm}$ (Figure 6). Accordingly, these hybrids beads are suitable to be packed into the treatment column to be utilized for continuous treatment operation.

3.2. Dye Decolorization Properties of Zinc Oxide Polymeric Hybrid Beads. The feasibility of the formulated $\mathrm{ZnO}$ polymeric hybrid beads for C.I. basic blue 41 dye decolorization from synthetic waste streams was examined. The applicability of the synthesized microbeads for dye removal was tested as a function of the different factors that affect the dye sorption process including the variation in contact time (0-120 min), initial dye concentration (1-100 ppm), dosage of $\mathrm{ZnO}$ hybrid

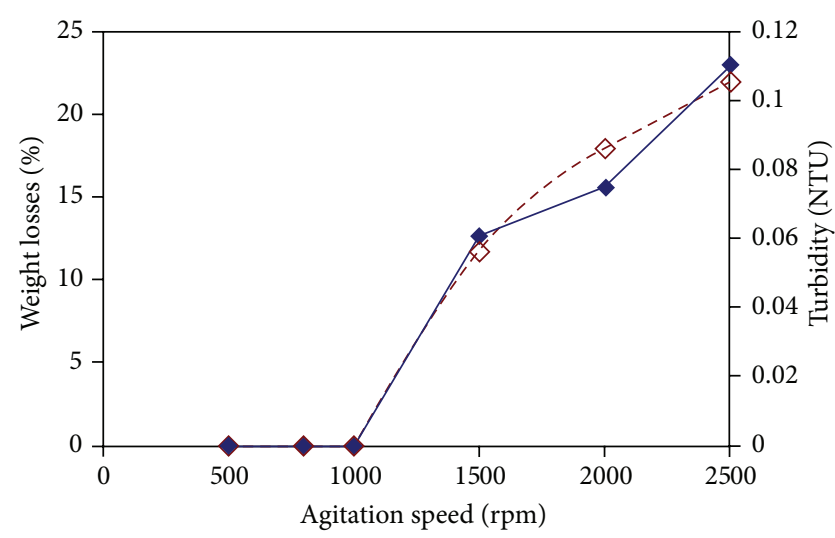

FIGURE 6: Mechanical stability of prepared $\mathrm{ZnO}$ polymeric hybrid beads at various mixing speeds.

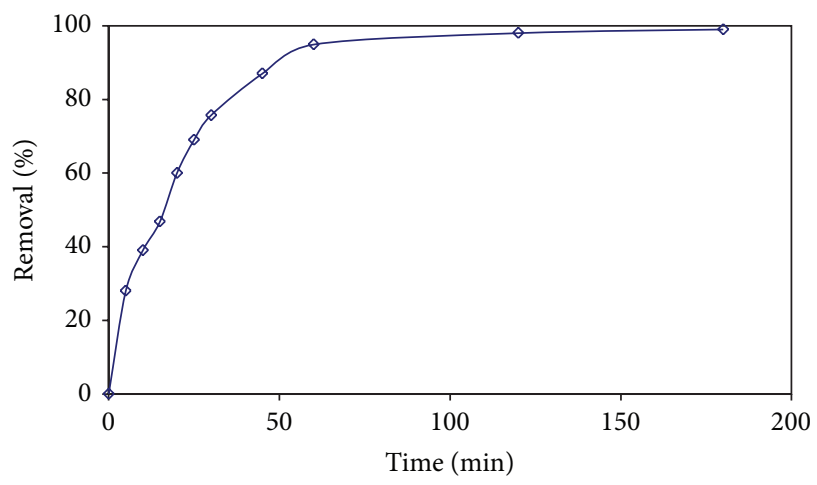

FIGURE 7: Effect of contact time on dye sorption process $(\mathrm{pH}=$ 6 , initial dye concentration $=10 \mathrm{ppm}$, agitation speed $=400 \mathrm{rpm}$, $\mathrm{ZOHB}$ dosage $=5 \mathrm{~g} / \mathrm{L}$, and temperature $=22^{\circ} \mathrm{C}$ ).

beads (1-10 g/L), dye solution $\mathrm{pH}(1-9)$, and dye solution temperature $\left(25-80^{\circ} \mathrm{C}\right)$.

3.2.1. Effect of Contact Time on the Dye Sorption Process onto $\mathrm{ZnO}$ Hybrid Beads. The effect of contact time on the adsorption of the basic blue dye onto zinc oxide hybrid beads was investigated over 120 minutes of time intervals. It can be noticed from Figure 7 that the removal of dye by adsorption onto $\mathrm{ZOHB}$ was found to be rapid at the initial period of contact time and then to slow down with time until reaching a constant value where no more dye was removed from the solution. At this point, the amount of dye being adsorbed onto the adsorbent was in a state of dynamic equilibrium with the amount of dye desorbed from the adsorbent. The time required to attain this state of equilibrium was termed the equilibrium time and the amount of dye adsorbed at the equilibrium time reflected the maximum dye adsorption capacity of the adsorbent under these particular conditions [41]. Figure 7 investigates that the equilibrium time of dye sorption onto $\mathrm{ZOHB}$ was recorded within 60 minutes.

3.2.2. Effect of $\mathrm{ZnO}$ Hybrid Beads on the Dye Sorption Process. The effect of $\mathrm{ZOHB}$ dosage on both the percentage dye 


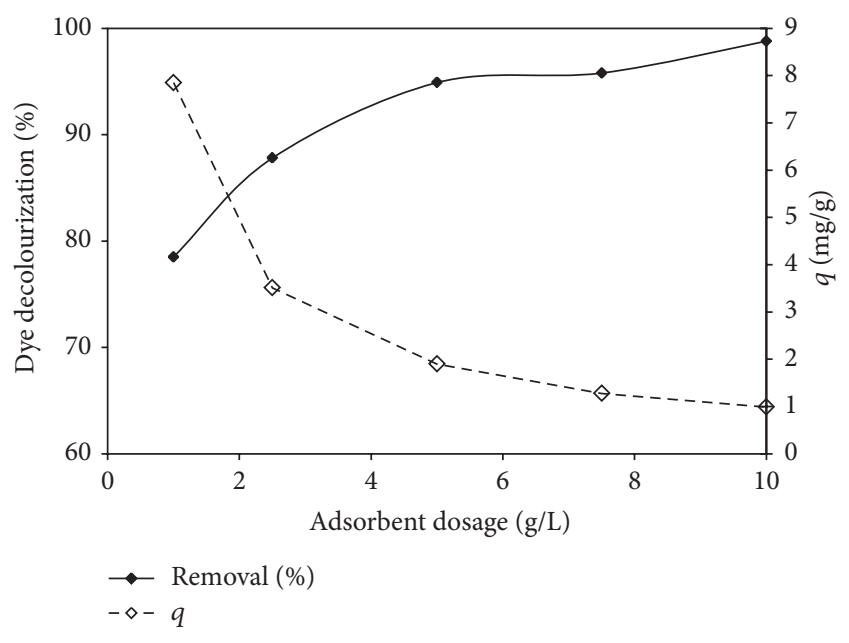

FIGURE 8: Effect of $\mathrm{ZnO}$ hybrid beads dosage on both the percentage of dye decolourization and dye uptake capacity $(\mathrm{pH}=6$, initial dye concentration $=10 \mathrm{ppm}$, agitation speed $=400 \mathrm{rpm}$, contact time $=$ $60 \mathrm{~min}$, and temperature $=22^{\circ} \mathrm{C}$ ).

removal and the beads sorption capacity was examined after 60 minutes. Figure 8 indicated that the percentage of dye decolorization was enhanced from 78.5 to $98.8 \%$ as $\mathrm{ZOHB}$ improved from 1 to $10 \mathrm{~g} / \mathrm{L}$ as well as an emphasized decrease being noticeable for the beads sorption capacity with increasing their concentrations. The decrease in unit adsorption with increasing beads concentration is basically due to adsorption sites remaining unsaturated during the adsorption reaction [41, 42]. Meanwhile, the improvement in the ZOHB dosage increases the adsorbent surface and the availability of more adsorption sites for dye removal. The optimum $\mathrm{ZnO}$ hybrid beads dosage that achieved the optimum dye decolourization percentage of $94.9 \%$ has been recorded from Figure 8 to be equal to $5 \mathrm{~g} / \mathrm{L}$.

3.2.3. Effect of Initial $\mathrm{pH}$ on Dye Adsorption Process. The $\mathrm{pH}$ of the dye solution plays an important role in the whole adsorption process. The dye adsorption process is highly $\mathrm{pH}$ dependent especially for the cationic dye adsorption [43]. The adsorption of these positively charged dye groups onto the adsorbent surface is primarily influenced by the surface charge of the adsorbent which in turn is affected by the $\mathrm{pH}$ of solution. Many oxide surfaces create a surface charge (positive or negative) [44]. Zinc oxide as most of metal oxide materials has an amphoteric character in aqueous medium; that is, it has hydroxyl groups only in acidic solutions ( $\mathrm{pH} 4$ and 6) and is converted into an anionexchanger as the solution $\mathrm{pH}$ improved above 6 [45]. In this regard, the initial $\mathrm{pH}$ of the dye solution was studied within $\mathrm{pH}$ range from 1 to 9 and all other parameters were kept constant. Figure 9 investigates that, at the high acidic dye solution (low $\mathrm{pH}$ value), the percentage dye sorption removal was increased but with low limitations from $18 \%$ to $45.5 \%$ as the dye $\mathrm{pH}$ value increased from 1 to 3 . Thereafter, the decolorization process increases rapidly and reaches a maximum level of $94.9 \%$ at the $\mathrm{pH}$ of 6 . As the dye solution

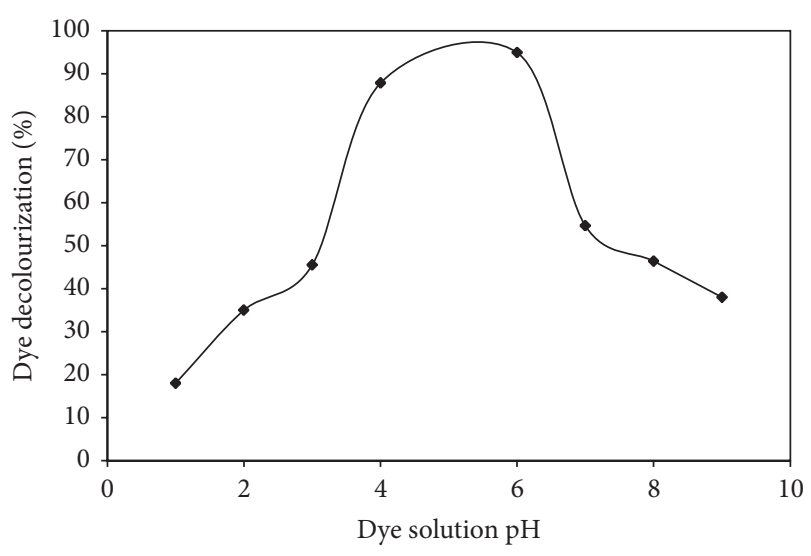

FIGURE 9: Effect of dye solution $\mathrm{pH}$ on the percentage of dye decolourization (initial dye concentration $=10 \mathrm{ppm}$, ZOHB dosage $=5 \mathrm{~g} / \mathrm{L}$, agitation speed $=400 \mathrm{rpm}$, contact time $=60 \mathrm{~min}$, and temperature $=22^{\circ} \mathrm{C}$ ).

$\mathrm{pH}$ incremented above value 6 , the dye sorption removal dramatically decreased. These three different dye sorption behaviours may be explained as, at low $\mathrm{pH}$ value, the lower dye sorption onto $\mathrm{ZOHB}$ may be due to the presence of excess $\mathrm{H}^{+}$ions competing with the positive groups on the dye for the beads adsorption sites. As the solution $\mathrm{pH}$ increased (above 3 ), the active surface sites of the immobilized $\mathrm{ZnO}$ onto the hybrid beads are deprotonated and the competition between $\mathrm{H}^{+}$and dye cationic for the adsorption sites lessens, which increase the dye adsorption amount. So, the higher dye uptake values obtained at higher $\mathrm{pH}$ (above 3 ) values are due to the electrostatic attractions between the positively charged dye anions and the immobilized negatively charged $\mathrm{ZnO}$ [46]. As the solution $\mathrm{pH}$ incremented above 6, the immobilized $\mathrm{ZnO}$ nanospecies were positively charged and converted into an anionic-exchanger; accordingly, electrostatic repulsion forces between the $\mathrm{ZOHB}$ and the dye anions will be induced that decrease the dye uptake onto the hybrid beads.

3.2.4. Effect of Initial Dye Concentration Process. The effect of initial dye concentration on the equilibrium adsorption capacity $\left(q_{e}\right)$ was carried out in the range of $1-100 \mathrm{mg} / \mathrm{L}$ at $\mathrm{pH}$ 6 using $5 \mathrm{~g} / \mathrm{L}$ from the ZOHB for $1 \mathrm{~h}$. The effect of initial dye concentration on the basic dye equilibrium adsorption capacity $\left(q_{e}\right)$ and removal efficiency were illustrated in Figure 10. This figure explores that there is linear enhancement in the dye sorption capacity as the initial concentration of the dye is increased from 1 to $100 \mathrm{mg} / \mathrm{L}$, which is in accordance with the previous studied researches [47]. The improvement in the dye sorption capacity as the initial dye concentration incremented was companied with a lower removal efficiency of the basic blue dye. This may be due to the saturation of the adsorption sites on the $\mathrm{ZnO}$ beads as the concentration of the dye increases. According to these results, the formulated zinc oxide hybrid beads are effectively capable of removing the C.I. basic blue 41 dye in solutions of a wide region of dye concentration completely. 


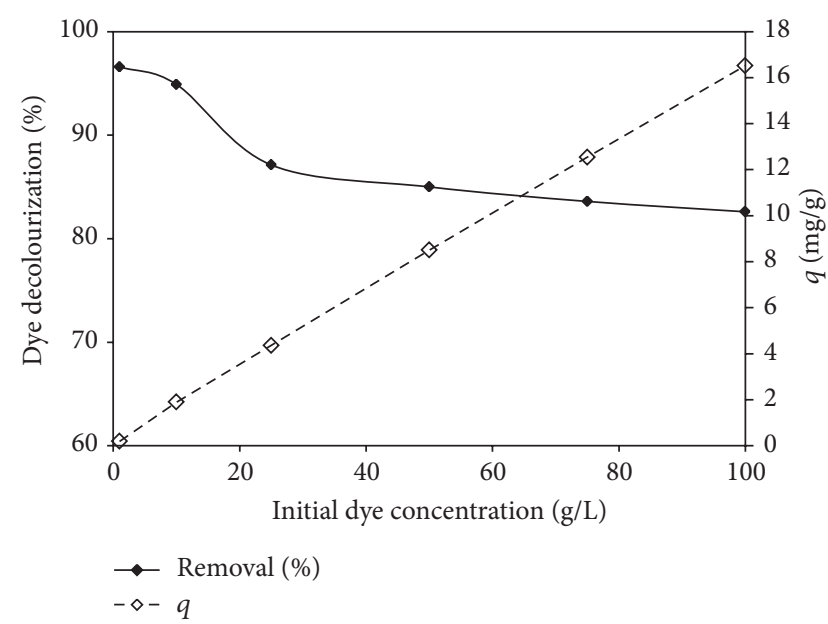

FIGURE 10: Effect of initial dye concentration on both the percentage of dye decolourization and dye uptake capacity $(\mathrm{pH}=6, \mathrm{ZOHB}$ dosage $=5 \mathrm{~g} / \mathrm{L}$, agitation speed $=400 \mathrm{rpm}$, contact time $=60 \mathrm{~min}$, and temperature $=22^{\circ} \mathrm{C}$ ).

\subsubsection{Effect of Solution Temperature on Dye Adsorption} Process. Temperature is well known to play an important role during the adsorption processes. It can affect several aspects of adsorption, for example, dye solubility, the swelling capacity of the sorbent, and the equilibrium position in relation to the endo- or exothermicity of the adsorption phenomenon [48]. So, the effect of temperature on the equilibrium basic blue dye adsorption onto the synthesized $\mathrm{ZOHB}$ was investigated in the temperature range of $25-80^{\circ} \mathrm{C}$. The increment in the dye solution temperature has a negative effect on the dye adsorption process onto the prepared material as predicted from Figure 11. This indicated that the adsorption of the basic blue dye onto the synthesized ZOHB is an exothermic process. The decrease in the rate of adsorption with the increase in temperature may be attributed to the tendency of dye molecules to escape from the solid phase to bulk phase with the improvement in solution temperature [49]. Accordingly, it was reliable that the dye sorption process onto the fabricated composite beads is not favorable at the elevated dye solution temperature (above $25^{\circ} \mathrm{C}$ ). This result may be explained by the deactivation of the zinc oxide polymeric beads surface or the destruction of some polymeric active sites on the adsorbent surface due to bond rupture [50].

Temperature dependence of the dye adsorption process onto $\mathrm{ZOHB}$ is associated with various thermodynamic parameters. To study the thermodynamics of the adsorption process, the standard Gibbs free energy of the process was evaluated by [51]

$$
\Delta G^{\circ}=R T \ln k_{c} .
$$

The equilibrium constant $k_{c}$ was evaluated at each temperature using the relationship

$$
k_{c}=\frac{C_{\mathrm{Be}}}{C_{\mathrm{Ae}}},
$$

where $C_{\mathrm{Be}}$ and $C_{\mathrm{Ae}}$ represent the equilibrium concentrations of dye on the $\mathrm{ZOHB}$ adsorbent and solution, respectively.

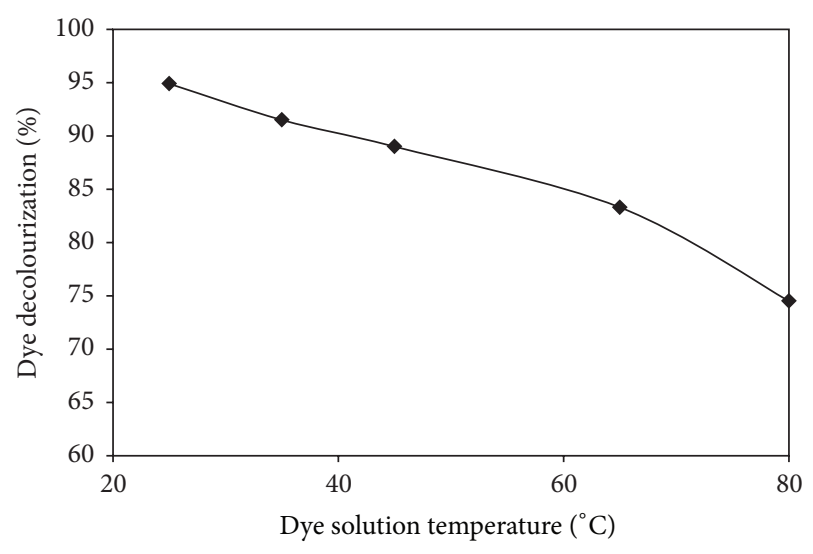

FIGURE 11: Effect of dye solution temperature on the percentage of dye decolourization (initial dye concentration $=10 \mathrm{ppm}, \mathrm{ZOHB}$ dosage $=5 \mathrm{~g} / \mathrm{L}$, agitation speed $=400 \mathrm{rpm}$, contact time $=60 \mathrm{~min}$, and $\mathrm{pH}=6)$.

TABle 3: Thermodynamic parameters for dye adsorption onto ZOHB.

\begin{tabular}{lccc}
\hline$T(\mathrm{~K})$ & $\Delta G^{\circ}\left(\mathrm{kJ} \mathrm{mol}^{-1}\right)$ & $\Delta H^{\circ}\left(\mathrm{kJ} \mathrm{mol}^{-1}\right)$ & $\Delta S^{\circ}\left(\mathrm{J} \mathrm{mol}^{-1} \mathrm{~K}^{-1}\right)$ \\
\hline 298 & -7.24 & & \\
308 & -6.08 & -2.07 & -4.199 \\
318 & -5.53 & & \\
338 & -4.62 & & \\
353 & -3.15 & & \\
\hline
\end{tabular}

Standard enthalpy $\left(\Delta H^{\circ}\right)$ and entropy $\left(\Delta S^{\circ}\right)$ were determined from the Van't Hoff equation:

$$
\ln k_{c}=\frac{\Delta S^{\circ}}{R}-\frac{\Delta H^{\circ}}{R T},
$$

where $\Delta H^{\circ}$ and $\Delta S^{\circ}$ were obtained from the slope and intercept of the plot of $\ln k_{c}$ versus $1 / T$ as shown in Figure 12 and listed in Table 3 . Values of free energy changes $\Delta G^{\circ}$ are negative, confirming that the dye adsorption process onto $\mathrm{ZOHB}$ is spontaneous and thermodynamically favorable. The decline in the negative values of $\Delta G^{\circ}$ with the improvement in temperature decreases the driving force at the adsorption process. Accordingly, the improvement in temperature has negative impact on the dye sorption process. The value of $\Delta H^{\circ}$ is negative, indicating that the adsorption process is exothermic in nature, while the negative value of entropy change $\left(\Delta S^{\circ}\right)$ shows a decreased disorder at the solid/liquid interface during dye sorption. As the temperature increases, the mobility of dye ions increases causing the ions to escape from the solid phase to the liquid phase. Therefore, the amount of dyes that may be adsorbed will be decreased [51].

3.3. Equilibrium Isotherm Analysis of Dye Adsorption Process. Equilibrium data, commonly known as adsorption isotherms, are basic requirements for the design of adsorption systems [52]. In this regard, the equilibrium data for BB41 on the fabricated hybrid beads were modeled using the wellknown isotherm models of Langmuir and Freundlich models. 


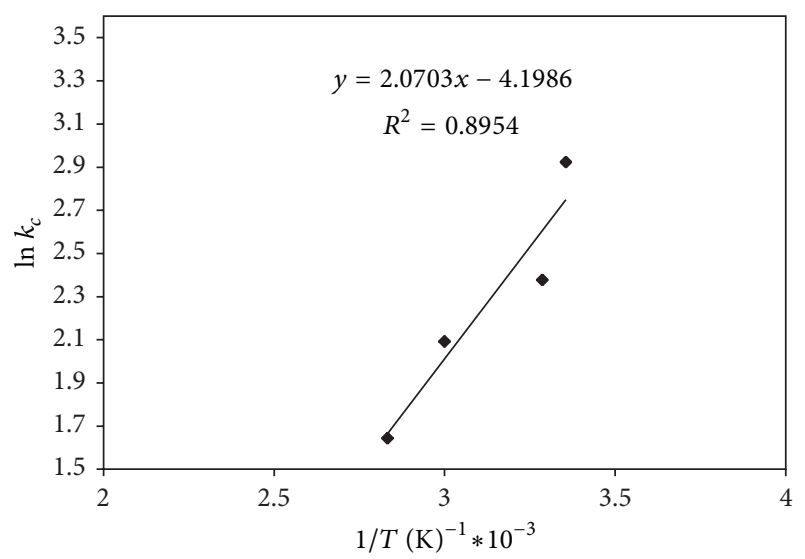

FIgURE 12: Arrhenius plot for dye sorption onto ZOHB at different solution temperatures (initial dye concentration $=10 \mathrm{ppm}, \mathrm{ZOHB}$ dosage $=5 \mathrm{~g} / \mathrm{L}$, agitation speed $=400 \mathrm{rpm}$, contact time $=60 \mathrm{~min}$, and $\mathrm{pH}=6$ ).

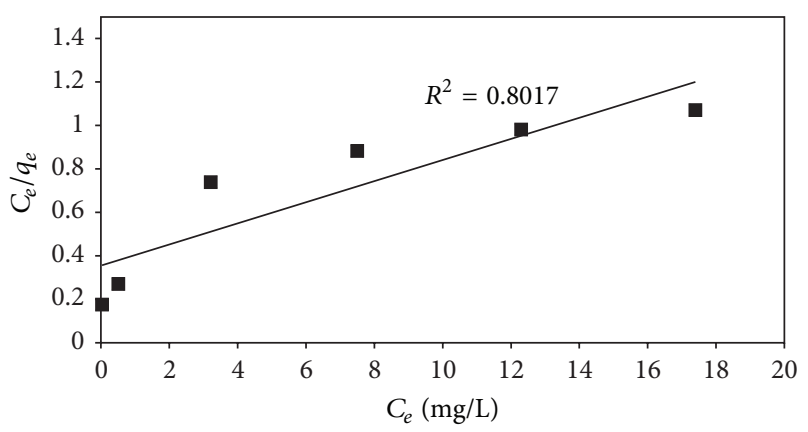

FIGURE 13: Langmuir isotherm for BB41 dye adsorption onto ZOHB.

The plot of $C_{e} / q_{e}$ versus $C_{e}$ (Figure 13) indicates a straight line with low value of the correlation coefficient $\left(R^{2}=0.8017\right)$ for the linearized plot of the equation that is represented as [53]

$$
\frac{C_{e}}{q_{e}}=\frac{1}{q_{m} K}+\frac{C_{e}}{q_{m}},
$$

where $q_{e}$ is the amount adsorbed $(\mathrm{mg} / \mathrm{g}), C_{e}$ is the equilibrium concentration of the adsorbate ions $(\mathrm{mg} / \mathrm{L})$, and $q_{m}$ and $K$ are Langmuir constants related to maximum adsorption capacity (monolayer capacity) $(\mathrm{mg} / \mathrm{g})$ and energy of adsorption $(\mathrm{L} / \mathrm{mg})$, respectively. Accordingly, the Langmuir isotherm model may be not adequate to describe the dye sorption process onto the fabricated zinc oxide hybrid beads.

Consider that Langmuir isotherm model assumes a monolayer coverage and uniform activity distribution on the adsorbent surface, which represent unexpected behavior for the decolorization of studied case onto the fabricated beads. However, the adsorption of basic blue dye onto ZOHHB beads suggested being a quite complex process, probably through forming multilayers and even closing some of the available pores at the bead surfaces [54]. Also, a variation of sorption activity is expected with surface coverage. So it can be expected that the Freundlich isotherm model was more suitable to describe the experimental data compared

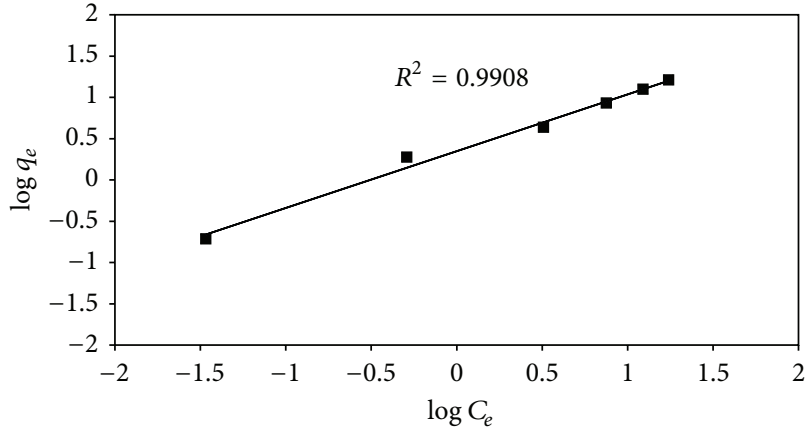

FIGURE 14: Freundlich isotherm for BB41 dye adsorption onto ZOHB.

with Langmuir model. The linearized form of the Freundlich equation may be expressed as [41]

$$
\ln q_{e}=\ln K_{F}+\frac{1}{n_{f}} \ln C_{e}
$$

where $K_{F}$ and $n_{f}$ are Freundlich constants related to adsorption capacity and adsorption intensity, respectively. The Freundlich constants are related to the surface heterogeneity. Figure 14 investigates the Freundlich linear fit for the dye sorption process onto the fabricated hybrid beads. It is obvious that the correlation coefficient value $\left(R^{2}=0.991\right)$ obtained through Freundlich isotherm is higher than that of the Langmuir fitting. So, Freundlich model was more appropriate for the prediction of the isothermal profiles for the basic dye sorption process onto the zinc oxide polymeric hybrid beads. This observation suggested that the sorption process is heterogeneous in nature and accomplished with a nonuniform distribution of heat of adsorption. The calculated $n_{f}$ value that is equal to 1.45 was greater than unity and indicated that the dye sorption process onto $\mathrm{ZOHB}$ was favorable.

3.4. Kinetic Model of Dye Adsorption Process. The rate at which dissolved dye is removed from the aqueous solution by solid sorbents is essential to evaluate the adsorption kinetics using theoretical models in order to design and control the sorption process units. So, the applicability of the pseudofirst-order and pseudo-second-order models was tested for the adsorption of BB41 onto ZOHB. The best-fit model was selected based on the linear regression correlation coefficient, $R^{2}$, values. The Lagergren first-order equation is given as [55]

$$
\ln \left(q_{e}-q_{t}\right)=\ln q_{e}-k_{1} t
$$

where $q_{e}$ and $q_{t}$ are amounts of dye ions sorbed $(\mathrm{mg} / \mathrm{g})$ at equilibrium and at time $t(\mathrm{~min})$, respectively. $k_{1}\left(\mathrm{~min}^{-1}\right)$ is the first-order reaction rate constant. If the pseudo-firstorder kinetics is applicable to the experimental data, a plot of $\ln \left(q_{e}-q_{t}\right)$ versus $t$ should present a linear relationship, as investigated in Figure 15; the calculated values of $k_{1}$ and $q_{e}$ can be determined from the slope and intercept of the plot, respectively. The values of $R^{2}$ for the sorption of different 


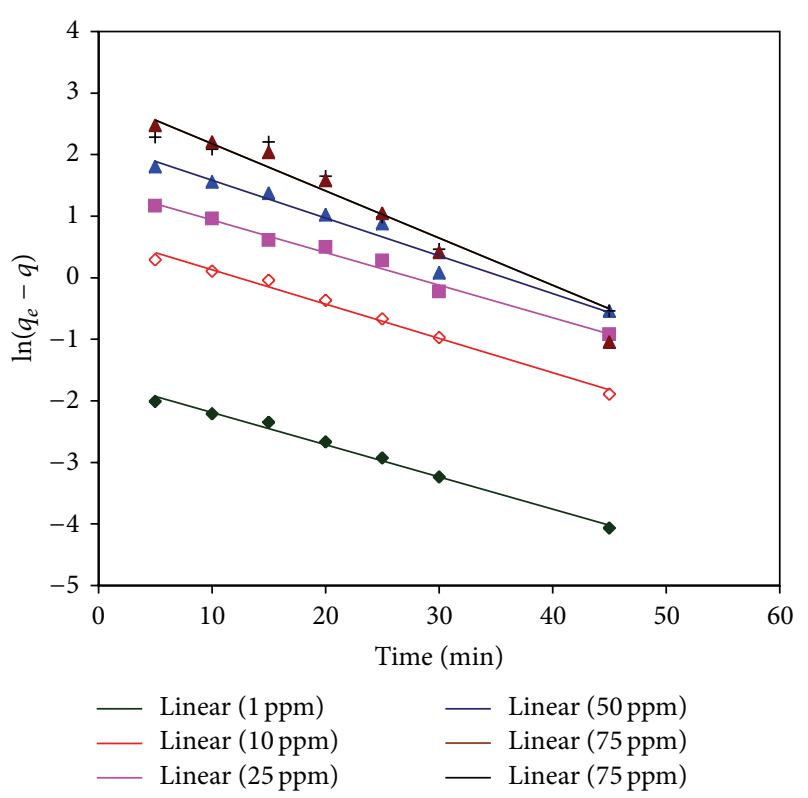

FIGURE 15: Pseudo-first-order kinetic model for BB41 dye adsorption onto ZOHB.

initial concentrations of basic blue dye ions onto $\mathrm{ZOHB}$ are tabulated in Table 4.

On the basis of linear regression values from this table $\left(R^{2}\right)$, it may be predicted that the kinetics of dye sorption onto ZOHB be described well by the first-order kinetic model. Comparing the values of $q_{e}$ calculated from the reaction kinetic curves (Table 4) with the experimental data, it is noticeable that the calculated $q_{e}$ values that were obtained from the first-order kinetic model were compatible with the experimental $q_{e}$ values. Thus, the first-order rate expression fits the data most satisfactorily. This gives prediction that the dye sorption process may take place basically through the physical sorption [56].

Moreover, the experimental kinetic data were further analyzed using the pseudo-second-order kinetic model that may be expressed in the following form [54]:

$$
\frac{t}{q_{t}}=\left(\frac{1}{k_{2} q_{e_{2}}}\right)+\frac{t}{q_{e}},
$$

where $k_{2}$ is the second-order reaction rate equilibrium constant (g/mg min). The plotting of $t / q t$ against $t$ for different initial BB41 concentrations (Figure 16) investigated straight lines with low values of correlation coefficients compared with the first-order rate model (Table 4) for the different studied dye concentrations especially for the high dye concentrations. Also, the estimated values of $q_{e}$ calculated from the equation differed from the experimental values. Accordingly, the first-order rate model is more appropriate to describe the dye sorption process onto the zinc oxide hybrid polymer compared with the second-order rate model.

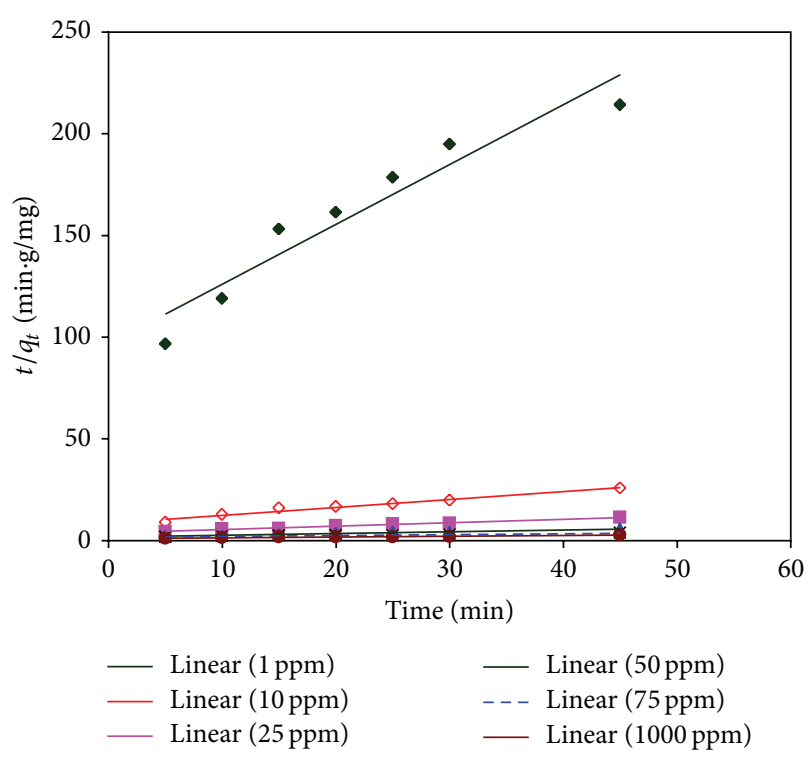

FIGURE 16: Pseudo-second-order kinetic model for BB41 dye adsorption onto ZOHB.

\section{Conclusion}

A novel fabricated microbead was successfully prepared from immobilization of the sol-gel synthesized zinc oxide nanopowder onto the PVA and alginate polymer matrix. The XRD and SEM results strongly support the physical interactions between zinc oxide nanoparticles and the polymer blend matrix. Furthermore, SEM examination and EDX analysis of the formulated hybrid beads confirm the incorporation of $\mathrm{ZnO}$ nanoparticles onto the polymeric hybrid matrix. Incorporation of polymeric matrix at the prepared zinc oxide hybrid beads decreases its thermal stability relatively compared with its immobilized pure zinc oxide. However, this polymer matrix has not any significant effect in the chemical and mechanical stabilities of the zinc oxide hybrid beads, where it is characterized by its good chemical and mechanical properties. The formulated hybrid beads have high dye adsorption performance for the C.I. 41 basic blue dye. The maximum dye sorption capacity was recorded as $16.5 \mathrm{mg} / \mathrm{g}$ using $100 \mathrm{ppm}$ initial dye concentration. The improvement in the beads dosage has positive impact on the percentage dye removal. Meanwhile, the increment in both initial dye concentrations and dye solution temperature has negative impact on the dye sorption process onto the fabricated beads. The experimental results and Van't Hoff equation plot confirm that the dye adsorption process is exothermic. The equilibrium isotherm data of the dye sorption process was described well using the Freundlich isotherm model. However, the kinetics of basic dye sorption process onto the fabricated hybrid beads obeys the pseudo-first-order kinetic model, indicating that the dye sorption process may take place basically through the physical sorption. 
TABLE 4: Kinetic parameters of dye adsorption onto ZOHB at different dye concentrations.

\begin{tabular}{lccccrrr}
\hline Kinetic model & \multirow{2}{*}{$\left(q_{e}\right)_{\text {exp }}(\mathrm{mg} / \mathrm{g})$} & \multicolumn{3}{c}{ Pseudo-first order } & \multicolumn{3}{c}{ Pseudo-second order } \\
Dye concentration $(\mathrm{mg} / \mathrm{L})$ & & $\left(q_{e}\right)_{\mathrm{cal}}(\mathrm{mg} / \mathrm{g})$ & $K_{1}\left(\mathrm{~min}^{-1}\right)$ & $R^{2}$ & $\left(q_{e}\right)_{\mathrm{cal}}(\mathrm{mg} / \mathrm{g})$ & $K_{2}(\mathrm{~g} / \mathrm{mg} \mathrm{min})$ & $R^{2}$ \\
\hline 1 & 0.193 & 0.19 & -0.052 & 0.99 & 0.34 & 0.089 & 0.958 \\
10 & 1.89 & 1.88 & -0.0053 & 0.98 & 2.56 & 0.018 & 0.967 \\
25 & 4.35 & 4.3 & -0.0053 & 0.98 & 5.87 & 0.0079 & 0.985 \\
50 & 8.5 & 8.9 & -0.006 & 0.966 & 11.67 & 0.0041 \\
75 & 12.54 & 18.9 & -0.076 & 0.94 & 22.98 & 0.975 \\
100 & 16.25 & 19.1 & 0.078 & 0.94 & 25.2 & 0.00114 \\
\hline
\end{tabular}

\section{Conflict of Interests}

The authors declare that there is no conflict of interests regarding the publication of this paper.

\section{Acknowledgment}

This work was funded by the Deanship of Scientific Research (DSR), King Abdulaziz University. Jeddah, under grant No. (135-021-D1434). The authors, therefore, acknowledge with thanks DSR technical and financial support.

\section{References}

[1] I. Kiran, T. Akar, A. S. Ozcan, A. Ozcan, and S. Tunali, "Biosorption kinetics and isotherm studies of Acid Red 57 by dried Cephalosporium aphidicola cells from aqueous solutions," Biochemical Engineering Journal, vol. 31, no. 3, pp. 197203, 2006.

[2] K. Vijayaraghavan and Y.-S. Yun, "Biosorption of C.I. Reactive Black 5 from aqueous solution using acid-treated biomass of brown seaweed Laminaria sp," Dyes and Pigments, vol. 76, no. 3, pp. 726-732, 2008.

[3] T. O’Mahony, E. Guibal, and J. M. Tobin, "Reactive dye biosorption by Rhizopus arrhizus biomass," Enzyme and Microbial Technology, vol. 31, no. 4, pp. 456-463, 2002.

[4] A. S. Özcan and A. Özcan, "Adsorption of acid dyes from aqueous solutions onto acid-activated bentonite," Journal of Colloid and Interface Science, vol. 276, no. 1, pp. 39-46, 2004.

[5] M. C. Ncibi, B. Mahjoub, and M. Seffen, "Kinetic and equilibrium studies of methylene blue biosorption by Posidonia oceanica (L.) fibres," Journal of Hazardous Materials, vol. 139, no. 2, pp. 280-285, 2007.

[6] T. Robinson, B. Chandran, and P. Nigam, "Removal of dyes from a synthetic textile dye effluent by biosorption on apple pomace and wheat straw," Water Research, vol. 36, no. 11, pp. 2824-2830, 2002.

[7] M. Roulia and A. A. Vassiliadis, "Interactions between C.I. Basic Blue 41 and aluminosilicate sorbents," Journal of Colloid and Interface Science, vol. 291, no. 1, pp. 37-44, 2005.

[8] I. A. W. Tan, B. H. Hameed, and A. L. Ahmad, "Equilibrium and kinetic studies on basic dye adsorption by oil palm fibre activated carbon," Chemical Engineering Journal, vol. 127, no. 13, pp. 111-119, 2007.

[9] H. C. Chu and K. M. Chen, "Reuse of activated sludge biomass: I. Removal of basic dyes from wastewater by biomass," Process Biochemistry, vol. 37, no. 6, pp. 595-600, 2002.
[10] B. S. Inbaraj, J. S. Wang, J. F. Lu, F. Y. Siao, and B. H. Chen, "Adsorption of toxic mercury(II) by an extracellular biopolymer poly( $\gamma$-glutamic acid)," Bioresource Technology, vol. 100, no. 1, pp. 200-207, 2009.

[11] G. McKay, “The adsorption of dyestuffs from aqueous solution using activated carbon: analytical solution for batch adsorption based on external mass transfer and," The Chemical Engineering Journal, vol. 27, no. 3, pp. 187-196, 1983.

[12] G. McKay, "Analytical solution using a pore diffusion model for a pseudo irreversible isotherm for the adsorption of basic dye on silica," AIChE Journal, vol. 30, pp. 692-697, 1984.

[13] S.-Y. Mak and D.-H. Chen, "Fast adsorption of methylene blue on polyacrylic acid-bound iron oxide magnetic nanoparticles," Dyes and Pigments, vol. 61, no. 1, pp. 93-98, 2004.

[14] R. Salehi, M. Arami, N. M. Mahmoodi, H. Bahrami, and S. Khorramfar, "Novel biocompatible composite (Chitosanzinc oxide nanoparticle): preparation, characterization and dye adsorption properties," Colloids and Surfaces B: Biointerfaces, vol. 80, no. 1, pp. 86-93, 2010.

[15] S. Park, J. C. Lee, D. W. Lee, and J. H. Lee, "Photocatalytic $\mathrm{ZnO}$ nanopowders prepared by solution combustion method for noble metal recovery," Journal of Materials Science, vol. 38, no. 22, pp. 4493-4497, 2003.

[16] Z. V. Marinković, O. Milošević, M. V. Nikolić et al., "Evolution of the microstructure of disperse $\mathrm{ZnO}$ powders obtained by the freeze-drying method," Materials Science and Engineering A, vol. 375-377, no. 1-2, pp. 620-624, 2004.

[17] H. Li, J. Wang, H. Liu, H. Zhang, and X. Li, "Zinc oxide films prepared by sol-gel method," Journal of Crystal Growth, vol. 275, no. 1-2, pp. e943-e946, 2005.

[18] R. Kaur, A. Singh, K. Sehrawat, N. Mehra, and R. Mehra, "Solgel derived yttrium doped $\mathrm{ZnO}$ nanostructures," Journal of NonCrystalline Solids, vol. 352, no. 23-25, pp. 2565-2568, 2006.

[19] M. M. Abd El-Latif and M. F. El-Kady, "Developing \& characterization of a new zirconium vanadate ion exchanger and its novel organic-inorganic hybrid," Journal of Applied Sciences Research, vol. 4, pp. 1-13, 2008.

[20] K. G. Varshney and A. H. Pandith, "Synthesis and ion exchange behavior of acrylonitrile-based zirconium phosphate-a new hybrid cation exchanger," Journal of the Indian Chemical Society, vol. 78, no. 5, pp. 250-253, 2001.

[21] A. A. Khan, A. Khan, and I. Inamuddin, "Preparation and characterization of a new organic-inorganic nano-composite poly-o-toluidine Th(IV) phosphate: its analytical applications as cation-exchanger and in making ion-selective electrode," Talanta, vol. 72, no. 2, pp. 699-710, 2007.

[22] A. Nilchi, H. Atashi, A. H. Javid, and R. Saberi, "Preparations of PAN-based adsorbers for separation of cesium and cobalt from 
radioactive wastes," Applied Radiation and Isotopes, vol. 65, no. 5, pp. 482-487, 2007.

[23] C. M. Hassan and N. A. Peppas, "Cellular PVA hydrogels produced by freeze/thawing," Journal of Applied Polymer Science, vol. 76, no. 14, pp. 2075-2079, 2000.

[24] B. Ramaraj, "Crosslinked poly(vinyl alcohol) and starch composite films. II. Physicomechanical, thermal properties and swelling studies," Journal of Applied Polymer Science, vol. 103, no. 2, pp. 909-916, 2007.

[25] B. Cruz-Ortiz, L. Ríos-González, Y. García, J. Rodríguez de la Garza, and J. Rodríguez-Martínez, "Immobilization of thermomyces lanuginosus lipase in PVA-alginate beads," Journal of Mexico Chemical Society, vol. 55, pp. 176-180, 2011.

[26] Z.-E. Long, Y. Huang, Z. Cai, W. Cong, and F. Ouyang, "Immobilization of acidithiobacillus ferrooxidans by a PVA-boric acid method for ferrous sulphate oxidation," Process Biochemistry, vol. 39, no. 12, pp. 2129-2133, 2004.

[27] W. Yujian, Y. Xiaojuan, L. Hongyu, and T. Wei, "Immobilization of Acidithiobacillus ferrooxidans with complex of PVA and sodium alginate," Polymer Degradation and Stability, vol. 91, no. 10, pp. 2408-2414, 2006.

[28] K.-M. Khoo and Y.-P. Ting, "Biosorption of gold by immobilized fungal biomass," Biochemical Engineering Journal, vol. 8, no. 1, pp. 51-59, 2001.

[29] H. Shokry Hassan, A. B. Kashyout, H. M. A. Soliman, M. A. Uosif, and N. Afify, "Effect of reaction time and Sb doping ratios on the architecturing of $\mathrm{ZnO}$ nanomaterials for gas sensor applications," Applied Surface Science, vol. 277, pp. 73-82, 2013.

[30] A. Mahmooda, S. Bano, S. GyunKim, and K. HoLee, "Watermethanol separation characteristics of annealed SA/PVA complex membranes," Journal of Membrane Science, vol. 415-416, pp. 360-367, 2012.

[31] K. T. Shalumon, K. H. Anulekha, S. V. Nair, S. V. Nair, K. P. Chennazhi, and R. Jayakumar, "Sodium alginate/poly(vinyl alcohol)/nano $\mathrm{ZnO}$ composite nanofibers for antibacterial wound dressings," International Journal of Biological Macromolecules, vol. 49, no. 3, pp. 247-254, 2011.

[32] F. F. Fang, J. H. Kim, and H. J. Choi, "Synthesis of core-shell structured $\mathrm{PS} / \mathrm{Fe}_{3} \mathrm{O}_{4}$ microbeads and their magnetorheology," Polymer, vol. 50, no. 10, pp. 2290-2293, 2009.

[33] J. Wang and L. Gao, "Synthesis and characterization of $\mathrm{ZnO}$ nanoparticles assembled in one-dimensional order," Inorganic Chemistry Communications, vol. 6, no. 7, pp. 877-881, 2003.

[34] S. Muthukumaran and R. Gopalakrishnan, "Structural, optical and photoluminescence studies of heavily $\mathrm{Mn}$-doped $\mathrm{ZnO}$ nanoparticles annealed under Ar atmosphere," Journal of Materials Science: Materials in Electronics, vol. 34, pp. 1946-1953, 2012.

[35] S. Amrut, J. Satish, S. Raghumani, J. Ahn, and B. Ramchandra, "Low temperature dielectric studies of zinc oxide $(\mathrm{ZnO})$ nanoparticles prepared by precipitation method," Advanced Powder Technology, vol. 24, pp. 331-335, 2013.

[36] K. Nakamoto, Infrared and Raman Spectra of Inorganic and Coordination Compounds, Parts A and B, John Wiley \& Sons, New York, NY, USA, 1997.

[37] M. S. Islam and M. R. Karim, "Fabrication and characterization of poly(vinyl alcohol)/alginate blend nanofibers by electrospinning method," Colloids and Surfaces A: Physicochemical and Engineering Aspects, vol. 366, no. 1-3, pp. 135-140, 2010.

[38] B. J. Holland and J. N. Hay, "The thermal degradation of poly(vinyl alcohol)," Polymer, vol. 42, no. 16, pp. 6775-6783, 2001.
[39] V. I. Lozinsky and F. M. Plieva, "Poly(vinyl alcohol) cryogels employed as matrices for cell immobilization. 3. Overview of recent research and developments," Enzyme and Microbial Technology, vol. 23, no. 3-4, pp. 227-242, 1998.

[40] M. Abd El-Latif, M. El-Kady, M. Ibrahim, and M. E. Ossman, "Alginate/polyvinyl alcohol-kaolin composite for removal of methylene blue from aqueous solution in a batch stirred tank reactor," Journal of American Science, vol. 6, pp. 280-292, 2010.

[41] M. F. Elkady, A. M. Ibrahim, and M. M. A. El-Latif, "Assessment of the adsorption kinetics, equilibrium and thermodynamic for the potential removal of reactive red dye using eggshell biocomposite beads," Desalination, vol. 278, no. 1-3, pp. 412423, 2011.

[42] Y. Al-Degs, M. A. M. Khraisheh, S. J. Allen, and M. N. Ahmad, "Effect of carbon surface chemistry on the removal of reactive dyes from textile effluent," Water Research, vol. 34, no. 3, pp. 927-935, 2000.

[43] X. S. Wang, Y. Zhou, Y. Jiang, and C. Sun, "The removal of basic dyes from aqueous solutions using agricultural by-products," Journal of Hazardous Materials, vol. 157, no. 2-3, pp. 374-385, 2008.

[44] Y. Al-Degs, M. A. M. Khraisheh, S. J. Allen, and M. N. Ahmad, "Effect of carbon surface chemistry on the removal of reactive dyes from textile effluent," Water Research, vol. 34, no. 3, pp. 927-935, 2000.

[45] A. Demirci, E. Alver, K. Ada, and M. Ozcimder, "Liquid chromatographic column performance of $\alpha$-alumina prepared by the reaction between aluminium sulphate and urea in boiling aqueous solution and an application to the separation of some common anions," Bulletin of Pure and Applied Science C, vol. 23, pp. 21-37, 2004.

[46] V. Belessi, G. Romanos, N. Boukos, D. Lambropoulou, and C. Trapalis, "Removal of Reactive Red 195 from aqueous solutions by adsorption on the surface of $\mathrm{TiO}_{2}$ nanoparticles," Journal of Hazardous Materials, vol. 170, no. 2-3, pp. 836-844, 2009.

[47] Z. Aksu and G. Dönmez, "A comparative study on the biosorption characteristics of some yeasts for Remazol Blue reactive dye," Chemosphere, vol. 50, no. 8, pp. 1075-1083, 2003.

[48] M. Wawrzkiewicz, "Removal of C.I. Basic Blue 3 dye by sorption onto cation exchange resin, functionalized and nonfunctionalized polymeric sorbents from aqueous solutions and wastewaters," Chemical Engineering Journal, vol. 217, pp. 414425, 2013.

[49] T. G. Venkatesha, R. Viswanatha, Y. Arthoba Nayaka, and B. K. Chethana, "Kinetics and thermodynamics of reactive and vat dyes adsorption on $\mathrm{MgO}$ nanoparticles," Chemical Engineering Journal, vol. 198-199, pp. 1-10, 2012.

[50] H. D. Ozsoy, H. Kumbur, B. Saha, and J. H. van Leeuwen, "Use of Rhizopus oligosporus produced from food processing wastewater as a biosorbent for $\mathrm{Cu}(\mathrm{II})$ ions removal from the aqueous solutions," Bioresource Technology, vol. 99, no. 11, pp. 4943-4948, 2008.

[51] W. S. Wan Ngah and M. A. K. M. Hanafiah, "Adsorption of copper on rubber (Hevea brasiliensis) leaf powder: kinetic, equilibrium and thermodynamic studies," Biochemical Engineering Journal, vol. 39, no. 3, pp. 521-530, 2008.

[52] A. Özer and G. Dursun, "Removal of methylene blue from aqueous solution by dehydrated wheat bran carbon," Journal of Hazardous Materials, vol. 146, no. 1-2, pp. 262-269, 2007.

[53] M. M. Abd El-Latif and M. F. Elkady, "Equilibrium isotherms for harmful ions sorption using nano zirconium vanadate ion exchanger," Desalination, vol. 255, no. 1-3, pp. 21-43, 2010. 
[54] M. Abd El-Latif, M. Ibrahim, and M. El-Kady, "Adsorption Equilibrium, kinetics and thermodynamics of methylene blue from aqueous solutions using biopolymer oak sawdust composite," Journal of American Science, vol. 6, pp. 267-283, 2010.

[55] S. Lagergren, "About the theory of so-called adsorption of soluble substances," Kungliga Svenska Vetenskapsakademiens Handlingar, vol. 24, no. 4, pp. 1-39, 1898.

[56] M. M. Abd El-Latif and M. F. Elkady, "Kinetics study and thermodynamic behavior for removing cesium, cobalt and nickel ions from aqueous solution using nano-zirconium vanadate ion exchanger," Desalination, vol. 271, no. 1-3, pp. 41-54, 2011. 

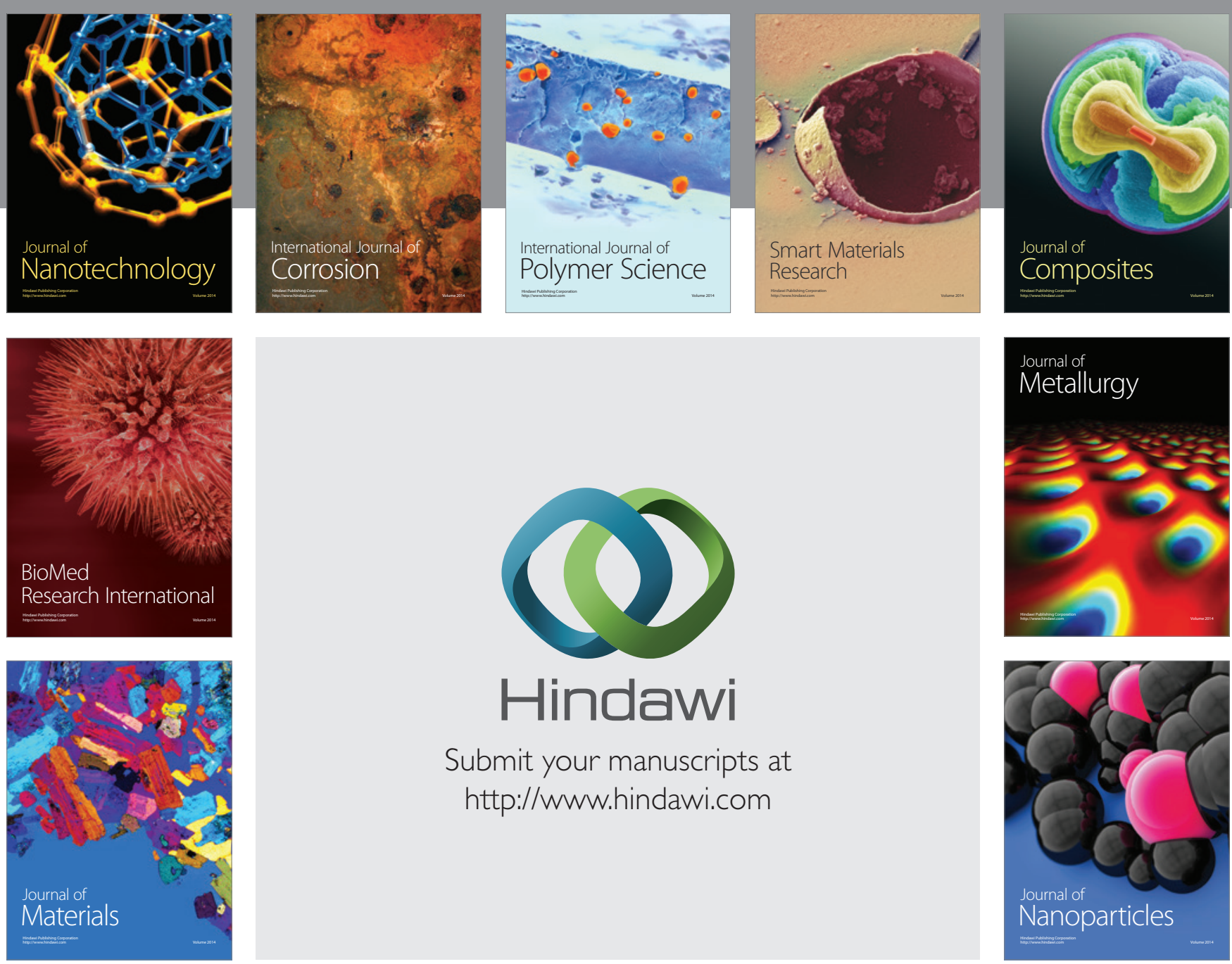

Submit your manuscripts at http://www.hindawi.com
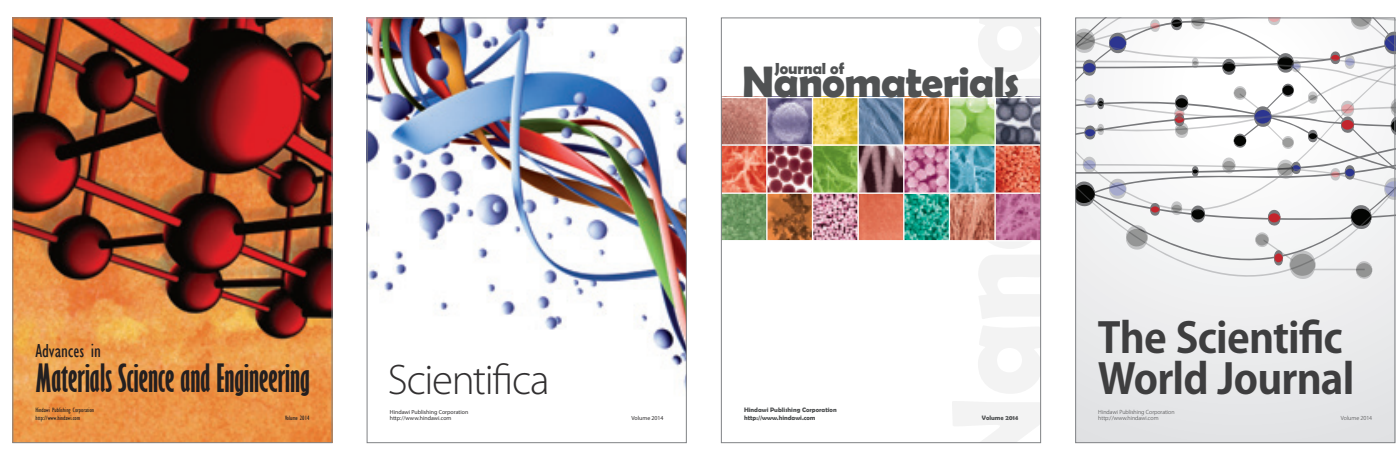

\section{The Scientific World Journal}
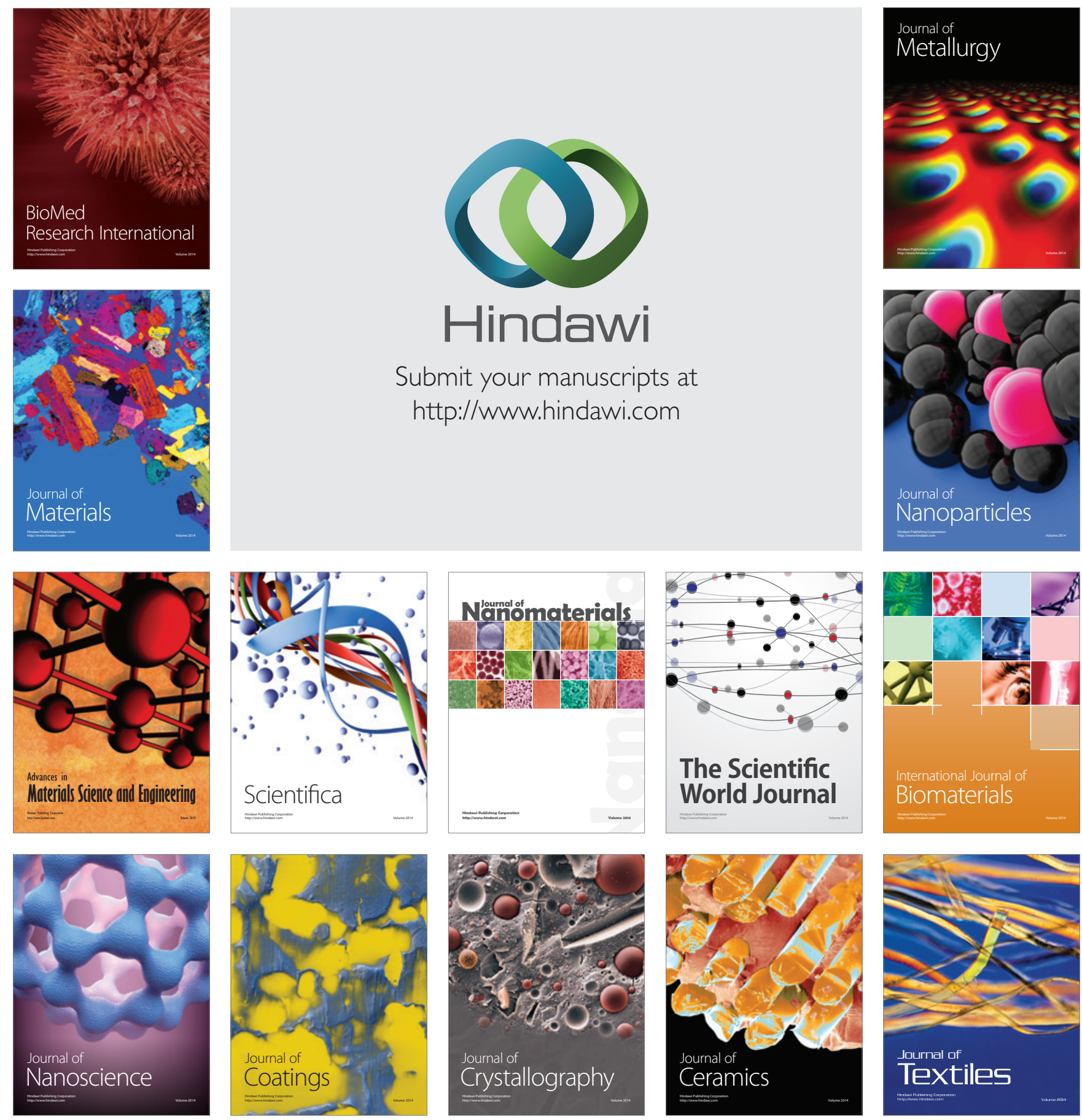